\title{
Current Instruction Situation and Reform Innovation in Advertising Design
}

\author{
Congrui Gao \\ Zhengzhou University of Light Industry \\ College of Art and Design \\ Henan Zhengzhou 450002 \\ e-mail: 89149808@qq.com
}

\begin{abstract}
-this paper analyzes the affecting factors on advertising design education development in fields of course arrangement, instruction modes based on current situation of Chinese advertising design education, uses the experience of foreign advertising design and education for reference, brings forward suggestions on reinforcement and improvement of advertising design education. Therefore, this paper aims to promote innovations of Chinese advertising design on promotion concept, teaching mode, cultivation objective, teaching methods, etc.
\end{abstract}

Keywords-advertising design; education innovation; discussion and analysis

\section{INTRODUCTION}

After China's reform and opening up especially entry into WTO, the rapidly-emerging economic constructions rise drastically and the alternation of information age industries impact all industries; large batches of foreign enterprises and products are introduced to China; meanwhile, some well-known advertising design companies had successively competed with domestic ones, which further aggravates industrial competition. Advertising design plays a quite important role in advertising competition. Demands of information age for modern advertising design talents require Chinese advertising design education to provide necessary talents for society as soon as possible.

\section{Current Instruction Situation of Advertising DESIGN}

\section{A. Modeling of Instruction Structure}

Currently, due to the effect of concept and conditions, the advertising education is still weak; especially the college graduates that should be main force of advertising design industry. They are required to possess broad knowledge reserves and strong innovative sense. However, college talents can't rapidly and efficiently serve for society because there are huge difference between college knowledge and social demands.

Most employees of advertising companies majors in art, visual communication, advertisement, etc. Except for certain aesthetic and artistic ability, these graduates are not familiar with market by lacking literal understanding and express ability, which obstructs smooth communication with advertising designers and clients. As for the high school instruction, domestic advertising emerges relatively late comparing with foreign industry. Most courses of advertising design in China are simple with quite similar course modes, forms and contents, which basically circle around conception, creative idea, elements, color, character, layout, etc. Furthermore, current teaching emphasizes particularly on systematic and theoretical instruction while class teaching takes inculcation education as main. [1]For a long time, most teachers rely on independent design idea, carefully execute their course plans based on teaching books or reference data compiled by other professors. Such excessive dependence destroys the exertion of teachers' creativeness.

\section{B. Excessively Single Course Arrangement}

Cognition difference on fundamental courses of advertising design affects the development of advertising design instruction. Most colleges run out of fundamental theoretical courses such as propagation, documents writing, public relations and psychology. Thus their students are short of literal express and planning ability, deficient creative idea, cross-subject and cross-media thoughts and implementation ability that should be possessed by high-end media design talents.

\section{Deficiency of Practice Ability}

Nowadays compound talents with strong comprehensive ability are highly welcomed. We often see some well-known enterprises market and the economy developed city was very cold to the graduate student, Most companies and enterprises are extremely interested in graduates with abundant experience, which shows that the college education can't meet social demands. [2] These should be completed by the school education for completed by a large number of small and medium-sized enterprises, small and medium-sized enterprises has become big business staff training base and talent reserve, this kind of phenomenon of long-standing and continued to heat up, these phenomena can see the serious defects in our school education. According to a survey conducted by the China advertising association, advertising thinks that there are several main problems in domestic advertising education schools. The degree of students is not only a little difference, and there is no experience. Student of advertising have some theory 
without practice. Therefore, advertising talents cultivation must be combined with practice. For understanding the present situation of advertising design and research in our country, in the future education of colleges and universities to find a road of sustainable development, will be our advertising enterprise's survival and development of the key. [3]Along with the acceleration of economic integration, the global economy brings forward severer requirements of talents. However, Chinese college education in advertising design is later than economic development. Therefore we must define cultivation objective, take instruction reform of advertising design, lay solid foundation of basic knowledge and improve professional ability, based on the forefront by facing the market, we must cultivate advertising talents accommodating modern economic development demands.

\section{Cultivating OBJective And TREnd of Advertising DESIGN TALENTS}

Presently excellent advertising talents should be provided with basic quality of pursing new knowledge and strong innovative ability. Scientific information and high technological means will become more and more important in advertising propagation. Besides basic knowledge learned from school, new generation advertising talents should be able to obtain new information with the fastest speed. Therefore, innovation ability is necessary for current advertising talents.

Modern advertising design is not only the expansion of single subject but also the multi-disciplinary and multi-fields development. This trend requires talents with solid foundation, strong innovative ability and advanced thought, as well as compound talents that grasp integrated marketing methods in an all-round way and skillfully apply various propagation media. [4]The comprehensive quality education provides talent cultivation basis, from which students can accumulate skills during leaning courses. As for students, such "Great Advertising Knowledge" will not only systematically exercise their comprehensive ability, but also cultivate them as a "Compound Talent". They must be skillful with advertising planning and design, industrial and commercial management, marketing and advertising, moreover, they should grasp knowledge of market, public relations, commodities, propagation, aesthetics, psychology, computer aided design, etc. Students must become a "Comprehensive Talent" and then breakthrough one subject to be a specialist. Such combination of "point" and "whole" will aid them to become skillful and comprehensive.

\section{INNOVATION OF COURSE SYSTEM AND INSTRUCTION MODE}

As an independent subject, the courses of advertising design should be arranged scientifically to build up a comprehensive and combined system that gives attention to both cultivation of students' quality, knowledge, ability, skill and concept and innovative education. On the other hand, advertising design instruction should apply open and multiple methods including heuristic, interactive, practice and unconventional teaching, based on instruction guideline of combination of theory and fact, we must achieve the aim of systematical learning and mastery of general theoretical knowledge and rules. As a result such a system should make students understand the whole course of practice and become a practical subject system and teaching mode that accommodates society and market economy better.

\section{$A$. integrating the subject and strengthening the basis}

As one of social sciences with strong adaptability, we set up comprehensive specialty and course of advertising design, which benefits to cultivate quality, thoughts, organization, communication and practice ability of modern talents. [5]Chinese college education especially advertising design education should emphasize its integral concept and thought. We must breakthrough conventions of short-term phase course, span over limits of different departments even colleges, realize interactive and inter-assistant communication between colleges and departments. Teachers from different universities can exchange title researches to strengthen communications.

\section{B. improving teachers' quality and optimizing teaching staff structure.}

Along with the economic development, the concept, method, medium of advertising design change increasingly. Teachers should learn new knowledge and accept new information to perfect their own knowledge system. [6] They will participate in social practice, introduce advanced teaching experience and resources, improve popularity and influence of college advertising specialty in advertising industry, pay attention to self and specialty propagation, and encourage other teachers and students to take industrial academic communications.

On the other hand, teaching staff structure is quite important. Author of this paper considers that we should use experience from America and Germany, while full-time teachers should only occupy $1 / 3$ of total staff; more social specialists as $1 / 3$ part-time workers should be engaged and the rest $1 / 3$ should be visiting professors from academy and other universities. This will be beneficial to resources optimization and initiative mobilization.

\section{C. building a comprehensive, forward-looking and open course system.}

We must establish modern teaching concept to train comprehensive talents. According to the actual situation of professional education in our school, learn the advantages of professional curriculum at home and abroad, we develop a comprehensive, forward-looking and open teaching course system, therefore, when determining the curriculum reform, we should consider the needs of the development of subject itself, social needs and the needs of the student individual, the curriculum should reflect the basis of extensive and professional personality tendency. We should fully consider the relationship between the advertising specialty course and other professional, to be able to reflect the development trend of advertising and various related disciplines, reflect the development of modern science and technology level. Appropriate to expand the proportion of elective courses and professional lectures, the latest information of the advertising industry and the latest research results timely introduction of the classroom. [7]As an interdisciplinary, the 
advertising design is benefiting from other subjects' achievements. To inherit this merit, comprehensive course shall be retained to form into multi-disciplinary courses combined with other subjects, so as to use advanced achievement and scientific research methods for reference. We must encourage marginal course to widen students' vision and broaden their thoughts. [8] Only if we adjust education concept, training model and course arrangement, we can efficiently enhance Chinese advertising education quality, satisfy the demands of high-speed development of enterprises in the early of 21 st century, as well as leading position of Chinese advertising industry in international advertising industry and business circles.

\section{D. achieving the diversity of teaching methods.}

Teachers should play roles of "guider, organizer and leader" especially for the advertising design education, they shall guide students' specialty study and interests, organize students to study independently and carry out practice. At present, Chinese advertising design educations mainly take single instruction and individual practice as main. We should discuss diverse and multi-level education mode such as advertising project-oriented method, self-organized student team, simulated competitive bidding flows of advertising company. Teachers should grasp the trend and steps and give some advice to different teams. [9]Students will actively join in such simulated interactive instruction, cooperate with each other, understand their deficiency and guide for future self-learning. Some colleges have achieved advanced diverse teaching methods. Jiangnan University had attempted to cooperate subjects with enterprises, which not only cultivates potential talents for enterprises but also provides valuable practice experience for students.

\section{CONCLUSION}

Achievements of Chinese advertising education are obvious, which not only appears as the increment of university quantity and expansion of school scale, but also embodies in specialization, professionalization and scientization, as well as remarkable enhancement of college quality and level. Nowadays, Chinese advertising education development transforms from "high speed" to "high quality", which is the inherent demand even necessary trend of Chinese advertising development.

\section{REFERENCES}

[1] Wei Ju: Problem and Solution of Chinese Higher Advertising Education in Mode Exploration, China Advertising Yearbook, 2004.

[2] Zhang Jinhai: Advertising Tutorial, Shanghai People's Publishing House, 2003.

[3] Huang Shengmin, Ding Junjie, etc. Deep Thought of Chinese Popular Advertising Education, Modern Advertisement, 1997.

[4] Hu Xiaoyun. Four Contradictions Plagued by Advertising in Our Country Higher Education [J]. Modern advertising, 2000.

[5] Liu Guoji. Perspective China Advertising Trends in 2004 [J]. Journal of International Advertising, 145, P11

[6] Chen Hongbo. Advertising Innovation Ability Training in the Education Practice [J]. Journal of Southeast Spread, 2010.3

[7] Fu Lin. Advertising Education in Colleges and Universities Personnel Training Mode Innovation [J]. Journal of Education Teaching Issue 2010.3

[8] Shu Yongping. New Media Ads Under the Trend of Education Innovation [J]. Journal of Advertising Observatory. 2008.4

[9] Zou Ming. About the Idea of Advertising Education Reform [J]. Journal of Shaanxi Education. 2007.12 